Retos y experiencias en la construcción de la Paz.

\title{
Aportes del Trabajo Social a la reconciliación nacional ${ }^{1}$
}

\author{
Contributions of social work to national reconciliation
}

\author{
Mónica Lucía Jiménez \\ Guatibonza \\ Corporación universitaria \\ Minuto de Dios Colombia \\ monilujimenez@gmail.com
}

\section{Resumen}

El texto busca evidenciar el uso de herramientas teóricas, conceptuales y metodológicas propias del Trabajo Social, así como los aportes sociopolíticos en el marco de la implementación del acuerdo para la finalización del conflicto y la construcción de una paz estable y duradera entre el Gobierno Colombiano y las Fuerzas Armadas Revolucionarias de Colombia - FARC. En el documento podremos identificar las habilidades teóricas y metodológicas que desde el Trabajo Social permiten a las y los profesionales construir análisis críticos de la realidad sociopolítica nacional y generar aportes propositivos para la transformación de la misma, así mismo se busca posicionar el quehacer de Trabajadoras y trabajadores Sociales en el marco de un escenario de reconciliación nacional.

\begin{abstract}
The text looks for to evidence the use of theoretical, conceptual and methodological tools characteristic of the Social Work, as well as the sociopolitical contributions in the mark of the implementation of the agreement for the termination of the conflict and the construction of a stable and durable peace between the Colombian Government and the Revolutionary Armed forces of Colombia - FARC. In the document we will be able to identify the theoretical and methodological abilities that allow the professionals to build critical analysis of the sociopolitical national reality and to generate contributions for the transformation of the same one from the Social Work, it is looked for to position the chore of Workers and Social workers in the mark of a scenario of national reconciliation.
\end{abstract}

${ }^{1}$ Recibido: 24/08/2018 Evaluado: 13/09/2018 Aceptado: 18/09/2018 
Palabras clave: Trabajo Social, memoria, reconciliación, FARC, Dimensión política del Trabajador social, Acuerdo de Paz.

Keywords: Social Work, memory, reconciliation, FARC, political Dimension of the social Worker, Agreement of Peace.

\section{Introducción}

Reconocer que los procesos sociales han ido deconstruyendo espacios para la paz, la reconciliación y la transformación de conflictos es imperante para identificar las estrategias de no violencia desde diferentes ámbitos y actores sociales hasta la utilización de métodos y metodologías alternas entre las que se incluyen las memorias colectivas como parte de los movimientos de verdad, justicia, reparación y reconciliación que se llevan a cabo en diversos países del mundo y particularmente en América Latina.

La memoria es definida por la RAE como "La facultad psíquica por medio de la cual se retiene y recuerda el pasado; una explosión de hechos, datos o motivos referentes a determinado asunto". Es así que nuestra memoria es selectiva en particular con situaciones que nos afectan y la podemos hacer extensiva a los acontecimientos sociales y políticos que se presentaran de manera colectiva, por ejemplo el conflicto armado colombiano, donde emergieron por una parte, discursos y prácticas encausados a olvidar para proceder a la reconciliación, y por otra, alocuciones y praxis sobre la memoria de los horrores de las dictaduras para generar conciencia, establecer responsabilidades, hacer justicia, y no olvidar para que no vuelva a suceder.

La implementación del Acuerdo, como fenómeno engendrado ajeno al accionar de la sociedad es de gran complejidad y, en cierto sentido, incomprensible para muchas personas, lo cual provoca un sentimiento de rechazo, que se expresa no solo en frases peyorativas sobre las FARC o el Acuerdo firmado, sino que además se vio reflejado en las urnas en el plebiscito realizado en el año 2016 en el que a la pregunta: ¿Apoya el acuerdo final para la terminación del conflicto y construcción de una paz estable y duradera? El 50,21\% de la población sufragante respondió $\mathrm{NO}$; sin embargo, este resultado no fue producto de la memoria colectiva o individual de la ciudadanía colombiana, días después de la jornada plebiscitaria se develó un plan de desprestigio al Acuerdo, que influyó de forma significativa en el resultado, esta campaña incluía difamaciones que desinformaron a la ciudadanía, suscitando el voto negativo de la colectividad.

Como trabajadoras y trabajadores sociales en este momento histórico debemos desarrollar capacidades Analítico-críticas, que permitan cuestionar el modelo estatal, aportando una crítica constructiva a la política social existente y presentando las reflexiones pertinentes para la elaboración de nuevas políticas y acciones afirmativas que sean incluyentes y diferenciales con los actores del conflicto armado en el país, entrando en confrontaciones interdisciplinarias que propicien la construcción intersectorial de la real paz estable y 
duradera, pues si bien es cierto que el acuerdo incluye modificaciones en las dinámicas económicas, políticas y sociales del país, también es claro que a partir del plebiscito se ha agudizado la polarización entre los partidos de derecha y un cantidad significativa de colombianos que respaldando el acuerdo de paz han sido considerados de "izquierda ideológica"; entendiendo el impacto que este panorama puede generar en el proceso de implementación, es pertinente que profesionales del Trabajo Social aporten desde la academia y los diferentes campos de acción las herramientas y metodologías propias que resguarden el acuerdo para la terminación del conflicto, así mismo es importante la vinculación de la profesión en las mesas de diálogo instalada con el Ejército de Liberación Nacional, ELN.

El quehacer de Trabajadoras y Trabajadores sociales tiene la particularidad de contar con un amplio campo de intervención que facilita la versatilidad de profesionales en diferentes campos de conocimiento privilegiados, constituyendo así una profesión en constante reconceptualización a través de la sistematización de sus objetos de estudio. Además, estos objetos están compuestos por los instrumentos de navegación específicos que permiten el desarrollo de la labor en caso, grupo y comunidad. En el caso de la implementación del Acuerdo para la terminación del conflicto y la construcción de una paz estable y duradera entre el Gobierno Colombiano y las Fuerzas Armadas Revolucionarias de Colombia - FARC, el objeto de conocimiento está enmarcado en la comprensión e inmersión epistemológica del paradigma crítico social en el ejercicio político y social, que define un conjunto de ideas, acciones y relaciones que determinan los intereses fundamentales de unos u otros sujetos políticos y su relación e impacto en la sociedad colombiana, atendiendo a la ya mencionada memoria colectiva, a la historia contada, y a elementos claves como la justicia, la verdad y la reparación.

Para darle una definición de objeto a nuestra labor como Trabajadores sociales en esta coyuntura, es importante comprender que el Trabajo Social interviene un mismo objeto material Hombre-Sociedad, pero lo que marca la diferencia con las otras ciencias sociales es el objeto formal sobre el cual se trabaja y la naturaleza de la acción investigativa y práctica del Trabajo Social y este a su vez varía de acuerdo al paradigma desde el cual se realice la intervención. Definir el problema objeto de intervención es delimitar que aspectos de una necesidad social son susceptibles de modificar con nuestra intervención profesional. (Iamamoto, 1997).

Por ejemplo, si abordamos la implementación del Acuerdo de Paz bajo el paradigma crítico social, el objeto de intervención es el estado como elemento propio de la cuestión social, gestor y regulador social y la sociedad como beneficiaria o afectada por dicha implementación o gestión.

Para Marilda Iamamoto el Trabajo Social tiene una indefinición positiva relacionada con 'qué es' o 'qué hace' el Servicio Social, positiva en el sentido que genera a Profesionales Sociales la posibilidad de presentar propuestas de trabajo que sobrepasen meramente la demanda institucional, accionar clave para la realidad instalada en el marco del conflicto armado colombiano. Tal característica, aprehendida a veces como un estigma profesional, puede ser reorientada en el sentido de una ampliación de su campo de autonomía, de acuerdo con la concepción social del agente sobre su práctica (1997:95). Para Iamamoto, y desde una 
configuración dialéctica, esta vaguedad sobre el Trabajo Social se presenta como la posibilidad de construcción del ejercicio profesional, entendiendo que aunque se han presentado diferentes firmas de acuerdos de paz en el mundo, la dinámica de las sociedades, el origen del conflicto armado y el desarrollo del mismo son tópicos que propician situaciones únicas que requieren de la innovación en las formas de intervención profesional ya que cada casuística es un desafío que incluye diversidad de aspectos de la realidad social a investigar y sistematizados de forma adecuada, nutren nuestra intervención de forma reveladora.

Los trabajadores y las trabajadoras sociales tenemos una deuda societal, no sólo con el trabajo social, sino, con los sujetos-agentes-actores sociales en el nombre de los cuales se legitimó, institucionalizó y reconceptualizó -aunque de manera inconclusa- el trabajo social, (Barrantes, 1979) y si logramos trabajar el punto que converge de las propuestas societales de innegable sentido étnico-popular, que están estremeciendo los cimientos oligárquicos, modernos y hasta posmodernos de gran parte de nuestros países, estaremos colocándonos en situación de poder comenzar a encarnar un verdadero Trabajo Societal.

El enfoque diferencial del Trabajo social, debe evidenciarse desde el marco de la investigación, que constituye un método que permite la observación y reflexión sistemática sobre realidades sociales (teóricas o no) usando para ello diferentes tipos de documentos que permiten la contextualización de la situación, lejos de dogmas, criterios personales o juzgamientos, para así poder interpretar la realidad tal y como es y no como creemos o queremos que sea.

La labor realizada de esta forma, permite indagar, interpretar, controvertir y presentar datos e informaciones sobre el contexto, utilizando para ello el análisis; teniendo como finalidad obtener resultados que pudiesen ser base para el desarrollo de discursos, ponencias, puntos de vista, entrevistas, proyectos de ley y demás argumentos que le apunten a definir los ajustes institucionales requeridos para aproximarnos a la reconciliación nacional, entendida esta como un nuevo marco de convivencia política, económica y social.

Como Trabajadores y trabajadoras sociales debemos reconocer que nuestro quehacer investigativo siempre está "localizado", que el sujeto y la subjetividad están presentes en todos nuestros procesos, que la memoria colectiva no se puede modificar, pero si se puede resignificar, que la indeterminación coexiste con el orden, que no existe una única manera de entender el método científico y que una verdad no es aplicable en todas las comunidades porque las realidades sociales son dinámicas y esto amerita que el desarrollo de las estrategias sea casi único; de esa forma podemos proponer la formulación de proyectos, planes y programas con un cambio de rumbo que venga determinado por los propios actores que toman conciencia de sus diferencias y favorecen tanto el encuentro como el conflicto y sus formas de enriquecimiento y motor de cambio conocido como "modelo endógeno e intercultural” (Moreno Domínguez, 2002)

Es imperante partir de la conceptualización de la vulnerabilidad social para enfocarnos posteriormente en una de sus principales dimensiones, desde nuestra labor como trabajadores(as) sociales debemos aportar a la interconectividad humana fomentando leyes que se formulen desde lo humano teniendo en cuenta las particularidades de diversas zonas y entendiendo la gobernabilidad como un concepto de carácter nacional, pilar para la 
reconciliación, que debe tener en cuenta las características multiculturales y pluriétnicas y las dinámicas que las encierran. Un claro ejemplo de ello radica en las relaciones entre el Estado y las organizaciones sociales y los debates que permean esta relación, las organizaciones sociales en las regiones apartadas de Colombia surgen en su mayoría en oposición a los gobiernos y en un afán ineludible por suplir las carencias de sus comunidades, es por ello que el análisis del lugar que ocupa la economía social en la estructura burocrática actual, debe ser una prioridad tanto en la investigación como en la intervención, evitando que las políticas nacionales estén formuladas desde la economía y medios de producción y excluyendo el impacto que éstas generan en los habitantes de la nación cuyo bienestar en teoría es el "deber ser" de la estructura administrativa del estado.

Frente a estos fenómenos de orden nacional y mundial las y los trabajadores sociales debemos intervenir con una postura crítica, analítica, propositiva y ávida de conocimiento y capacitación que aporten a la teoría y a la construcción de nuestra profesión.

Esta construcción se debe realizar desde tres ámbitos de análisis: "el factual o comportamental (qué se hace), el narrativo (qué se dice sobre lo que se hace) y el interpretativo (motivos para y por qué) para así develar sus significados contempla la posibilidad de influir y ser influido, conjugar interpretación y acción, significar permanentemente la situación y, por ende, generar nuevos aprendizajes a partir de la misma intervención" (Ordóñez Pinzón, 2011).

Asimismo, los cambios en el modo de organización e intervención estatal, a partir del desmantelamiento y privatización del sistema de seguridad social y de las prestaciones sociales que habían sido conquistados por los trabajadores décadas atrás, en términos de derechos sociales y de la imposición de pautas para la gestión de políticas sociales por parte de los organismos de crédito internacionales (Banco Mundial, BID) suponen nuevas formas de tratamiento de la cuestión social, imponiendo nuevos requerimientos a los trabajadores sociales en términos de saberes y habilidades para la acción profesional.

Entendemos la dimensión política de la profesión como la búsqueda de la explicación profunda de las coordenadas socio-históricas que determinan el trabajo profesional. Para ello, vemos como imprescindible la comprensión del capitalismo como sistema económico y político mundial interdependiente, donde las particularidades nacionales, provinciales, municipales y locales, representan en sí una combinación de los rasgos fundamentales de esta totalidad. Desde esta perspectiva, podemos entonces organizar estrategias de intervención en la "singularidad" de las situaciones que enfrentamos cotidianamente en nuestros ámbitos laborales, que intenten dar respuestas (siempre parciales y acotadas) a las demandas y necesidades de las organizaciones y sujetos con los que trabajamos.

La praxis social es lo que diferencia al Trabajo Social de otras disciplinas sociales, es el contacto directo, cotidiano y continuado con la realidad social, su actuación junto con la humanidad en su misma realidad histórica y la planificación de cara al futuro. El trabajo social es una disciplina critica por sí misma, para que sea efectiva en su quehacer es necesario llegar a la misma realidad social, para conocerla, a través de la investigación y de la intervención social. 


\section{Referencias}

Andrade, Eduardo. (1987). Teoría General del Estado. México, D.F. :Colección Textos Jurídicos Universitarios.

Barrantes, César. (2006). El trabajo social de siglo veintiuno. Una crítica al discurso brasileños et alii en Revista Katálisys, volumen 9, No. 2, segundo semestre. Florianópolis, Brasil: Universidad de Santa Catarina.

Coraggio, José Luis. (2003). Los Estados deben marcar el rumbo económico. Pennsylvania: Editorial Claridad.

Garay, Luis. (2017). Repensar a Colombia: Hacia un nuevo Contrato Social”. Bogotá, Colombia: PNUD.

Iamamoto, Marilda y otros. (2002). Intervención profesional frente la actual cuestión social. Buenos Aires, Argentina: Editorial Espacio.

Piedrahita, Carlos Arturo. (2006). Políticas Públicas en Colombia. Bogotá, Colombia: Editorial Temis.

Repetto, Fabián. (2009). Coordinación de políticas sociales: abordaje conceptual y revisión de experiencias latinoamericanas en "Proyecto de Modernización del Estado de la Jefatura de Gabinete de ministerio de la Nación”. La Rioja, España: Unirioja.

Sandoval, Eduardo. (2016). Educación para la paz integral. Bogotá: Editorial Arfo.

Vargas, Alejo (2009). Construcción del estado-nación en Colombia. Bogotá, Colombia: El colombiano. 